\title{
Special Issue: Dedicated to the Memory of Pierre Hohenberg
}

\section{Joel Lebowitz ${ }^{1}$}

Published online: 15 April 2019

(c) Springer Science+Business Media, LLC, part of Springer Nature 2019

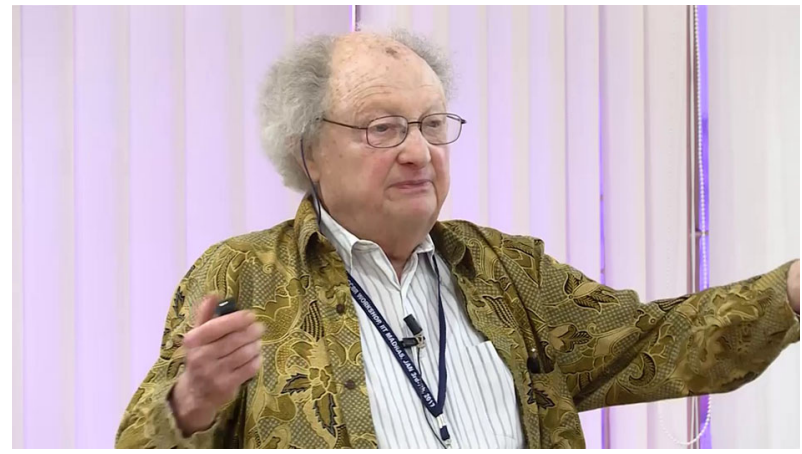

\section{Guest Editors:}

Daniel S. Fisher

Department of Applied Physics

Clark Center S264

318 Campus Drive

Stanford, CA 94305

Email: dsfisher@stanford.edu

Bertrand I. Halperin

Harvard University

Department of Physics

17 Oxford Street

Cambridge, MA 02138

Email: halperin@physics.harvard.edu

Wim van Saarloos

Institute-Lorentz for Theoretical Physics

Leiden University

Joel Lebowitz

lebowitz@math.rutgers.edu

1 Center for Mathematical Sciences Research, Rutgers, The State University of New Jersey, Piscataway, USA 
Niels Bohrweg 2

2333 CA Leiden

The Netherlands

Email: saarloos@lorentz.leidenuniv.nl

\section{Preface}

This issue of the Journal is dedicated to the memory of Pierre Hohenberg. Pierre was a friend, colleague and mentor to many of us in the statistical mechanics community. He was also a wonderful human being with many interests-in particular that of the human rights of scientists all over the world.

Please find below a statement from Jasna Brujic and Shura Grossberg about a non-technical memorial book for Pierre. His memory will always be with us.

The book entitled "Memories of Pierre Hohenberg", edited by Alexander Grosberg and Jasna Brujic, has been published online at https://physics.nyu.edu/pierre-hohenbergmemorial/

Pierre Hohenberg asked us to assemble this volume in his memory, stating that the emphasis in remembering him should not be on mourning, but on the celebration of his life, in which humor played a most significant role. This volume includes contributions from Pierre's wife, brother, colleagues, and friends. The authors were free to choose the style in which they remember Pierre: through anecdotes, biographical stories, science that was or continues to be inspired by Pierre, or even jokes. He did not set any limits on how short or how long the pieces should be, giving rise to an eclectic mixture of texts. Please feel free to distribute the memorial book widely, making sure Pierre's legacy lives on.

Publisher's Note Springer Nature remains neutral with regard to jurisdictional claims in published maps and institutional affiliations 